were design assistants or draughtsmen, testing, inspection and analysis accounting for $14 \cdot 4$ per cent.

Design and drawing office work accounted for 40.7 per cent of all vacancies for technicians $(67.5$ per cent in shipbuilding and marine engineering firms), but in the chemical industry $44 \cdot 6$ per cent of vacancies were for laboratory technicians for research and development. An analysis of requirements for the next two years presented a similar picture. In the chemical group of industries 63 per cent of tech- nicians had some qualification, and this group employed 43 per cent of all technicians with the General Certificate of Education at Advanced Level, while in the shipbuilding and marine engineering industry 58 per cent of technicians had a qualification. About 10 per cent of all the firms referred to apprentice. ships, technician, student or drawing office combined with courses at technical colleges for which release on one day a week was granted, but nearly 70 per cent replied that no courses of instruction were provided.

\title{
HEALTH OF BRITISH SCHOOL CHILDREN
}

“T HE great majority of school children are not only robust and healthy, but are taller and heavier than their predecessors", states Sir John Charles, the chief medical officer of the Ministry of Education, in his report for 1958 and 1959*.

Sir John says under-nutrition has almost disappeared in Britain, and the differences between the heights and weights of children in good and poor districts are lessening. More fat than under-nourished children are being reported, but the number in each group is small.

Only about five per cent of school children con. tracted a notifiable infectious disease in the years under review. Tuberculosis continued to decline. Poliomyelitis reached its lowest level for thirteen years, and vaccination against it was undertaken vigorously everywhere. There were local outbreaks of diphtheria that involved 47 school children in 1958, of whom five died; seventy-seven were affected in 1959 with no deaths. Advocating the continued need for immunization the report directs attention to the fact that "as recently as twenty years ago 55,000 persons contracted diphtheria annually, of whom almost 3,000 died".

The main cause of death among children is through accident. More children aged 5-15 years die from accidents than from all congenital malformations and of circulatory, genito-urinary infections and respiratory diseases altogether. In 1958, 869 children of 5-15 years died from accidents, including 395 from accidents involving motor vehicles, 174 from drowning, and 58 from burns and scalds; 113 fatal accidents took place in the home.

The second chief cause of death of children of this age-group is cancer. There were 499 deaths in 1958, mainly from leukæmia. Other causes were respiratory diseases, 253 ; congenital malformations, 185; infectious diseases, 137; genitourinary diseases, 76 ; and only 53 from diseases of the heart and blood vessels. More children died from appendicitis (44) than from rheumatic fever and rheumatic heart disease (30); these conditions were once widespread and deadly. The report stresses the need for unremitting research into the causes of the so-called congenital diseases and defects. "Medical research gives us reason to believe that some diseases that we consider hereditary or congenital in origin may well be found to be due to adverse influences in pregnancy or infancy." These diseases and defects cause the death each year of about 4,000 children under the age of fifteen

* The Health of the School Child: Report of the Chief Medical Officer of the Ministry of Education for the years 1958 and 1959 . Pp.
iii $+231+8$ plates. (London: H.M. Stationery Office, 1960.) $10 s .6 d$. net. years and leave thousands disabled. To this must be added those who are mentally retarded or who are blind or deaf from birth or early infancy. Although most children are healthy and without blemish, there are tens of thousands who are disabled to a greater or lesser degree.

The report welcomes the increasing number of education authorities which are considering, or who have already started, a modification of the fifty-year old system of periodical medical examination. In these areas all children will be examined after first starting and before leaving school ; but, instead of a periodical examination of intermediate age-groups, doctors will visit the schools more frequently and give more attention to the new children who appear to need it. The hope is expressed that school doctors will be able to give more time to the study of particular diseases and disabilities as they affect children at school. Illustrations given are respira. tory diseases-as many as 100,000 boys and girls have asthma some time during their childhoodand the nature and effects of skin diseases, from which tens of thousands of children are still reported to be suffering.

In 1958 more than two million children were examined at periodical school medical examinations. More than 809,000 were examined in schools and clinics at the special request of the parents, doctors, nurses, teachers, or others, and nearly $1,044,000$ were re-examined for defects found at a previous examination. The comparable figures for 1959 were $2,138,000 ; 704,000$ and $1,041,000$.

About 15 out of every 100 children who were examined after first starting school were found with some defects which required treatment; in some areas, from one in five to almost one in two of these were not receiving it. Often the parents did not know of the defect or did not appreciate its significance. Prevalence of defects found at periodical inspections shows that 175,000 are treated annually for skin diseases; 200,000 orthopædic defects, mostly slight; 15,000 boys and girls are under treatment for epilepsy; 2,000 boys and girls of school age have diabetes. There are fewer children with heart disease. Of every thousand boys and girls examined, twelve had a heart defect in 1958 compared with eighteen in 1948. The recorded prevalence of lung disease in school children has become almost stationary since 1948. Of every thousand children examined 24 were found with lung disease in 1948 and 25 in 1958.

Although the number of verminous children is still "deplorably high" $-219,000$ in 1958 and 223,000 in 1959 - it is less than half the figure of 464,000 in 1948. 
A small number of children attend school inadequately clad. There is, however, widespread com. ment about the unsuitable types of shoes worn by many children, especially older girls. A school doctor in Hertfordshire reported that younger children were well shod, but that "many girls of secondary school age would not be guided otherwise than by the dictates of fashion".

The report says that it is doubtful whether children will refrain from smoking so long as they see their parents and teachers enjoying the habit. A survey of about 3,500 boys and girls in two grammar schools and four modern secondary schools in a county borough near London shows that eight per cent of the children are 'regular' smokers-the smoking of five cigarettes a week being defined as regular for the purposes of the survey. One third of the children aged 14-16 who are 'regular' smokers smoke more than twenty cigarettes a week. Another survey carried out in Oxfordshire of about 8,300 children shows that nearly 1,600 are smokers and spend $£ 4,350$ a year on cigarettes. Nearly half these children say that they have heard that there is some connexion between cigarette smoking and lung cancer.

The report emphasizes that, generally, facilities are adequate for medical treatment, but are seriously inadequate for dental treatment; the national shortage of dentists is the main deficiency. The school dental service is able to treat only a little more than half the number of children who require treatment. A large number, many of whom attend non-maintained schools, are treated by the general dental service, but hundreds of thousands are neglected.

In 1959 , for the first time, the number of part. time dentists did not balance the number of wholetime dentists who retired or who left the service.

Special surveys of the teeth of the 5-12 year old children in eight representative areas show that deterioration of the teeth was less in five-year olds, but greater in twelve-year old children between 1953 and 1958 than between 1948 and 1953. "It is significant that during the period 1948-1958 sugar consumption per head in the United Kingdom rose from $88.3 \mathrm{lbs}$. in 1948 to $103 \cdot 1 \mathrm{lbs}$. in 1953 and $120.7 \mathrm{lbs}$. in $1958^{\prime \prime}$, states the report.
The report of the working party set up in 1949 "to direct and organize an investigation on the prophylactic effects of the local application of a solution of fluoride to school children's teeth", is published as an appendix to the report. The working party considers that the application of a fluoride solution to the teeth is not a worthwhile preventive measure in the conditions of the investigation, that is, when the treatment is given on a wide scale in the public dental service. This may well enhance the interest already being taken in alternative methods of caries prevention, such as tluoridation of drinking water and the dental health education of the public, and especially children, in such matters as proper diet and the cleansing of teeth.

A notable feature of the work of the School Health Service in the years under review is the increased attention given to children with emotional or be. haviour problems, and also of those with speech defects, but there was a serious shortage of child guidance clinic staff and of speech therapists. Much attention was paid to handicapped children; 54 new special schools, with accommodation for 5,732 children, were opened in 1958 and 1959, bringing the total number of handicapped children in special schools to more than 60,000 . Much interest, too, was taken in children with defective hearing, and an increasing number of local education authorities employed peripatetic teachers of the deaf to visit children in ordinary schools, or opened special classes in ordinary schools for partially hearing children. During this period a large number of the new Medresco transistor hearing aids were supplied to school children.

Sir John insists that a school health service cannot ignore the challenge of children from problem families, of those who have been before the courts, or of promiscuity among some older adolescents. These boys and girls formed a small minority of the school population, but they presented "a tough problem to the medical, education and social services-three services that must work together".

Appendixes to the report include, in addition to the usual statistical tables, a list of the research projects being undertaken in the school health service and an index to The Health of the School Child for the period 1935-57.

\section{STRENGTH AND PROPERTIES OF TIMBER}

$\mathrm{R}^{\mathrm{r}}$ ESEARCH into timbers is undertaken in England at the Forest Products Research Laboratory, Princes Risborough, and is under the auspices of the Department of Scientific and Industrial Research. F'orest Products Research Bulletin No. 45, entitled "The Strength and Properties of Timber", by F. H. Armstrong *, supersedes two earlier ones on the same subject and contains fresh material. Information on the properties of no fewer than 172 kinds of timber is presented in the proportion of some 37 home-grown timbers to 136 imported timbers, figures which may appear to some to be rather disproportionate, but the Laboratory has

* Pp. vi $+34+8$ plates. (London : H.M. Stationery Office, 1960.) 3s. $6 d$. net. done a useful service to Commonwealth countries while not actually ignoring home-grown material, which has been handled more intensively. The technique of timber-testing has made considerable advances in recent years, and one new development in England has been the adoption of the 'Monnin' system, which makes use of 2-cm. square instead of 2 -in. square test-pieces, and is thus more suitable for small-diamster trees.

The gist of this Bulletin consists of three tabular statements occupying about 16 pages. The physical and mechanical properties of home-grown timbers are given in Table 1 , those of imported timbers, based on 2-in. test-pieces, in Table 2, and those of imported timbers, based on 2.cm. test-pieces, in 